\title{
Protest Tactics and Motivations Surrounding Mountaintop Removal Mining in West Virginia
}

Craig Zell

Follow this and additional works at: https://researchrepository.wvu.edu/etd

\section{Recommended Citation}

Zell, Craig, "Protest Tactics and Motivations Surrounding Mountaintop Removal Mining in West Virginia" (2015). Graduate Theses, Dissertations, and Problem Reports. 7028.

https://researchrepository.wvu.edu/etd/7028

This Thesis is protected by copyright and/or related rights. It has been brought to you by the The Research Repository @ WVU with permission from the rights-holder(s). You are free to use this Thesis in any way that is permitted by the copyright and related rights legislation that applies to your use. For other uses you must obtain permission from the rights-holder(s) directly, unless additional rights are indicated by a Creative Commons license in the record and/ or on the work itself. This Thesis has been accepted for inclusion in WVU Graduate Theses, Dissertations, and Problem Reports collection by an authorized administrator of The Research Repository @ WVU. For more information, please contact researchrepository@mail.wvu.edu. 


\title{
Protest Tactics and Motivations Surrounding Mountaintop Removal Mining in West Virginia
}

\author{
Craig Zell \\ Thesis Submitted \\ to the Eberly College of Arts and Sciences \\ at West Virginia University
}

in partial fulfillment of the requirements for the degree of

Master of Arts in

Sociology

Daniel Renfrew, Ph.D., Chair

Jesse Wozniak, Ph.D.

Jennifer Steele, Ph.D.

Department of Sociology and anthropology

Morgantown, West Virginia

2015

Keywords: social movements, new social movement theory, Alberto Melucci, mountaintop removal mining, collective identity, tactics

Copyright 2015 Craig Zell 


\begin{abstract}
Protest Tactics and Motivations Surrounding Mountaintop Removal Mining in West Virginia
\end{abstract}

Social movements have been studied in a wide variety of ways. From the use of resource mobilization and political opportunity structure to the new social movement theories. In my paper I discuss how the use of identity and tactics is crucial in understanding how the social movement surrounding anti-mountaintop removal mining in West Virginia works. I studied two groups within this particular movement that use very different tactics as means to the same end. By analyzing them with the use of NSM theory I show how a multi-group approach to studying social movements gives a lot of information on the variance and nuance within the movement itself. This covers topics ranging from how they got involved to the tactics they and their group uses to what one groups' members think of another within their movement. 


\section{Table of Contents}

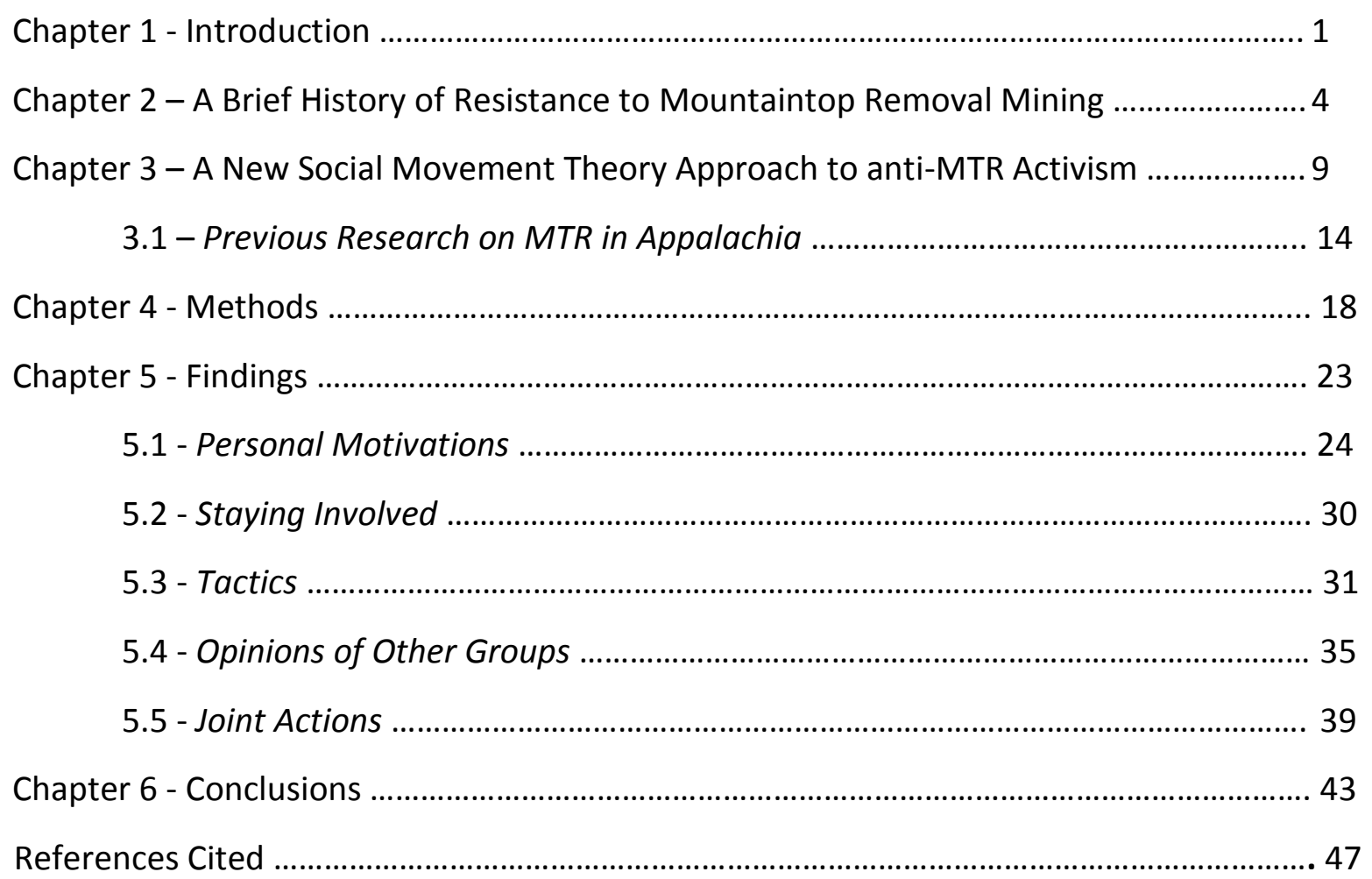




\section{Introduction}

On the weekend of October 24-26, 2014, Mountain Justice held their annual Fall Summit at Kayford Mountain. The Fall Summit is an annual weekend retreat aimed at building solidarity within the Mountain Justice group and networking with other groups. Kayford Mountain is roughly 50 miles southeast of Charleston, West Virginia, the state capital, and home to one of the largest mountaintop removal (MTR) mines in all of West Virginia. This was the first time I had ever seen an MTR site in person. It is something that I, along with many other first-timers, will never forget. Driving up through the forest to a public park at the edge of the property seems like an idyllic drive through the hills of West Virginia. However, just a short walk from the site where all the tents were erected, looms a barren, almost alien looking landscape that is at total odds with everything around it. Seven thousand five hundred acres have been methodically leveled leaving strange jutting ledges and unnatural blocks seemingly spaced at random. The first thing that is noticed after the initial shock of this baffling sight, is the complete lack of sound. An eerie hush lies over the area. There are no more birds, deer, squirrels, or any other signs of life in the area because there is nothing but bare, useless rocks.

After that unsettling experience everybody sluggishly walked back to the camp site, almost as if the air had been taken out of the stomachs of all who saw the former mine. Eventually chatter started back up the closer we got to camp. There was a solemn "Oh my God" uttered, and other disbelieving epithets. As the group processed what they had seen, and experienced, their quiet words of disapproval quickly became words of outright fury. 
On the previous day, there were workshops staffed by members of the anti-MTR grassroots groups Mountain Justice, Coal River Mountain Watch, and R.A.M.P.S., which detailed what exactly MTR is and what to expect on the hike the next morning. They covered issues ranging from non-violent direct action to militarism in West Virginia. Although the topics covered were rather "heavy" and densely packed, a relatively light atmosphere was maintained throughout the camp. Later that evening there was a bonfire, birthday jubilations, and networking between the groups for the newer members. There was live music, good oldfashioned moonshine, and lots of storytelling from the more experienced participants.

There was a more eclectic mix of people at this event than I had anticipated. As I expected there were the younger, college age newcomers and the older more experienced crowd, but there was more than that. Apart from the expected, the group even had tourists from Europe. The morning of the hike there were counter-protesters at the Kayford mine site. At the end of the weekend, it was clear to see that the experience had invigorated the younger participants and pleased the elders. Some students I spoke with mentioned how they knew what they were going to see, but "couldn't even imagine" the vastness of a 7,500 acre mine site. I could not agree more with that sentiment.

This event made a couple of important issues clear concerning environmental social movements and the socio-political makeup of this movement. While every person at that weekend could agree that they wanted to end mountaintop removal mining, there were heated debates about the proper way of going about this endeavor. The variance behind why these activists chose this issue was massive, and was a constant conversation starter. Everybody was 
genuinely interested in hearing what others had to say and how they learned about MTR and what they wanted to gain from their involvement in this anti-MTR movement.

My research is dedicated to trying to understand variants in protest tactics within the broader anti-MTR movement. Other studies conducted on mountaintop removal mining have focused on what mountaintop removal mining does to the environment, culture, and societies that are in Appalachia (Davis and Duffy 2009; Fox 1999; Holzman 2011; McNeil 2012; Morrone and Buckley 2011; Scott 2007, 2010; and Stimeling 2012), but there are still a lot of facets of this social movement that need to be studied.

My research focuses on the different tactics used by two of the anti-MTR groups in West Virginia. This was prompted by being a native of West Virginia and having heard both sides of this issue my entire life. Three questions drove this project: How and why do people join the anti-MTR movement? What makes them stay involved with the movement? How do members of particular groups view other anti-MTR groups operating within the same social movement?

I chose the Sierra Club and Mountain Justice because they represent two different approaches used in resisting the use of MTR in West Virginia. At West Virginia University in Morgantown, West Virginia there is a branch of the Sierra Club called the Student Sierra Coalition. Being based out of Morgantown made this an obvious choice. Since I met so many participants from Mountain Justice that weekend, that group was a natural second choice.

This thesis begins with some of the different types of anti-MTR groups in West Virginia and the historical context of protesting and social movements in the coal fields, from the coal field "wars" of the early $20^{\text {th }}$ century to the current protest movements. I then provide an 
overview of New Social Movement theory and explain why I chose this theory as my principal analytical approach. I next situate my research in relation to previous research conducted on environmentalism and the coal industry in West Virginia. Finally, I present the data I collected and analyze how it pertains to my research questions, examining in particular why a person joins one group over another within a heterogeneous social movement, and the intramovement dynamics at work in the broader anti-MTR struggle, including tactical debates between following direct action or reformist agendas.

\section{A Brief History of Resistance to Mountaintop Removal Coal Mining}

Mountaintop removal mining is a particularly invasive and destructive method of coal mining that began in the 1970's and became increasingly used throughout Appalachia since the early 1990's (Morrone \& Buckley 2011). Mountaintop removal mining is a used to extract coal from underneath what the industry refers to as "overburden" or "spoil" (Holzman 2011, A478; Palmer, Berhardt et al. 2010, 148). The process of mountaintop mining follows a fairly simple process: removal of vegetation, use of explosives to loosen the spoil, and draglines and other heavy machinery to remove spoil until the coal seam is reached (Holzman 2011). Concurrent with the MTR process comes the valley fill, which is where the spoil is hauled to and dumped until the mining operation stops (Davis and Duffy 2009).

There are a vast number of organizations on either side of the contentious debate that surrounds the use of mountaintop removal mining in Appalachia. Some of the most common phrases that can be seen on cars and t-shirts are "I love mountains" or "Friends of Coal". Upon 
seeing these phrases, or something similar, on somebody's personal belongings it is easy to tell on which side of the debate that person stands. However, it is hard to determine how much they really have invested in the cause or how informed they are about the issues that encompass coal mining.

Coal mining in West Virginia was historically one of the biggest job creators in the state. The coal companies often preyed upon the people of central Appalachia in order to get at the natural resources post- Civil War (Bell and York 2010, 119; Bell and York 2010; Wheeler 1976). The creation of company towns effectively turned Appalachian coal miners into indentured servants and caused the first organized resistance to the coal companies (Bell and York 2010; Wheeler 1976; Huber 2006; Lewis 1993). Ever since the Coal Wars in southern West Virginia during the early $20^{\text {th }}$ century, protesting has been a common and useful tool for people across the region.

After the Coal Wars there was little push back against mining until the 1960's and 1970's when surface mining began being used in Kentucky (Morrone \& Buckley 2011). This resistance initiated the anti-MTR movement throughout Appalachia. During this period residents of Harlan County and surrounding areas "engaged in nonviolent direct action as well as industrial sabotage" in an attempt to end surface mining (Morrone \& Buckley 2011, 82). This was the first time direct conflict between coal companies and landowners (non-mining families) occurred and became an issue to a much larger public (Morrone \& Buckley 2011).

These events eventually lead to the creation, signing, and implementation of the 1977 legislation called the Surface Mining Control and Reclamation Act (SMCRA) by Congress and 
President Jimmy Carter (Morrone and Buckley 2011, 83; McNeil 2012). Although the argument was originally for an all-out ban on surface mining, a compromise was reached which set down laws for the creation, operation, and reclamation of the mining sites. Lax enforcement of this bill ensured that the fight against surface mining would continue for a long time (Morrone \& Buckley 2011; McNeil 2012; Davis and Duffy 2009). While this was seen by many as a big win for activists who opposed mining, the activists themselves saw it as a poorly worded bill which would be nearly impossible to enforce (McNeil 2012; Morrone and Buckley 2011).

Even though the effectiveness of the bill was minimal, the public seemed to lose interest in the fight against MTR. The sudden and precipitous drop of activism surrounding mining in Appalachia, however, was not what it seemed. One possible explanation for the sudden stop was that the Independent Coal Operators Association (ICOA) fought against the protestors by alleging that "possible communist sympathizers" were involved with the protesting of mineral extraction (Morrone and Buckley 2011, 82). Where the mine companies thought they had won a victory and pushed back what they called the "outside agitators", all they had really done was buy themselves some time (Morrone and Buckley 2011; Fox 1999).

Julia Fox (1999) discusses how the proliferation of MTR mining in West Virginia during the 1990's was partly due to the amendment of the Clean Air Act. This piece of legislation requires less harmful emissions from coal burning plants in particular. West Virginia has large repositories of low-sulfur coal and the demand for this particular type of coal has skyrocketed due to the Clean Air Act (Fox 1999). One of the main reasons that Fox, among others, have deemed West Virginia an "environmental sacrifice zone" is due to how the mines are operated 
and the effects that this is having on the surrounding areas (Fox 1999). Fox defines an

environmental sacrifice zone as an area where the environment is destroyed methodically in order for humans to consume the minerals that are found there (Fox 1999, 165).

Between 1995 and 1998 more than 27,000 acres of mountaintops were permitted for MTR mining (Fox 1999, 165). As a result of such massive mining operations the land that is left is unstable, which causes landslides and floods and makes the ground unsuitable for native hardwood trees to regrow, causing an environmental disaster in its own right (Fox 1999, 166167). With the land being damaged by both the process of extracting the coal and then again by not being able to repair itself, the ecosystems at the tops of these mountains are permanently changed. This article puts a specific name to the way many of the people that are against MTR feel. They believe that both they and the mountains they love are being sacrificed in the name of the dollar and they wish to preserve what is left.

The groups that stand out the most and receive the most press are those that oppose, what is colloquially referred to as, King Coal (Scott 2010). Some of the big players in the movement against mountaintop removal mining have been written about before, such as in Bryan McNeil's Combatting Mountaintop Removal (2012) and Rebecca Scott's Removing Mountains (2010). McNeil focused on the well-known Coal River Mountain Watch (CRMW) and Scott's focus was on nature and identity within the area affected by MTR. Those two books show how various groups attack the same issue from a standpoint that coincides with their ideology. 
By researching the tactics and strategies that are used by various groups protesting the same issues, a broader understanding of this particular movement can be gained. The types of tactics used in social movements fall under two broad categories: the reformist approach (legislative change, conservation, tighter regulation) and the direct action approach (protests and marches to the more extreme forms like sabotage). The reformist approach tends to focus more on lawful disobedience in hopes of enacting legal change, while the direct action approach more frequently breaks the law in order to get their message heard. The two groups that I am researching are prime examples of this.

Mountain Justice is an organization that began in 2005 in hopes of raising worldwide awareness of MTR. This grassroots organization has bases throughout Appalachia and engages in direct actions against the use of MTR mining. Direct action is the process by which a group protests against an issue or a group that has power through a public demonstration of rallies, marches, sit-ins, strikes, or trespassing in order to get their point across to the appropriate figures. The Sierra Club is a national organization that was founded in 1892 and has slowly changed the focus of its environmental mission over time to reflect current issues. The focus changed from improving trails and building lodges in the Sierra Mountains in the 1920's to lobbying against oil pipelines in 2013. This group uses only lawful and reformist tactics in order to help preserve and restore the environment. I define reformist tactics as, methods of attempting to incur change through the use of protest, petition, and strikes that do not violate criminal laws. 
The authors above, and others, typically focus on one group when doing their research. Looking at a single group can result in data that is very rich in detail, but that sometimes assumes internal homogeneity, while the broader protest 'field' is directed towards groups the social movements are organizing against. The aim of researching multiple groups within a single social movement for a comparative study is to try to glean information about intra-movement diversity and variance, and how they not only position themselves in relation to external antagonists but also to their 'allies' within the broader social movement field.

The history of protesting in Appalachia informs the activism that restarted in the 1990's (McNeil 2012). A much greater number of reasons for resistance came with the reinvigorated movement to stop the use of MTR. Now, not only was personal property and job conditions at the top of the list of concerns but personal and community health, long term environmental concerns, the future of resource extraction, and damage to the culture within the Appalachian Mountains also joined the list (Fox 1999; Evans 2010; Holzman 2011; Palmer et al. 2010; Scott 2010; and Stimeling 2012). All of these issues are part of a larger protest field surrounding mountaintop removal mining and can fall under the scope of a single research theory, specifically New Social Movement theory.

\section{A New Social Movement Theory Approach to anti-MTR Activism}

Social movements are a collection of informal or formal networks between individuals and organizations which share a belief and use collective action to attempt to enact a social or political change (Della Porta and Diani 1999; Gahan and Pekarek 2013). The circumstances 
surrounding MTR in Appalachia meet these criteria. Multiple groups which are in contact with one another share the idea that MTR needs to be stopped and work both together and separately in order to achieve this goal (McNeil 2012; Morrone and Buckley 2011; Scott 2010). By using NSM theory a connection can be seen between the past forms of resistance on an issue and how they have been adopted into the new social movements (Edelman 2001; della Porta and Diani 1999). The phenomenon of coal related protesting has been examined previously, specifically focusing on the history of unions, resistance, and militancy of activists in Appalachia (Morrone and Buckley 2011; McNeil 2012).

I build upon this previous literature by studying the anti-MTR movement from the perspective of New Social Movement (NSM) theory. The emergence of NSM theory comes from a paradigm shift in the way social movements were being studied in the 1960 s, introducing a European perspective on social movements that deals primarily with culture, identity, and politics (Edelman 2001; Vahabzadeh 2001; Della Porta and Diani 1999; Melucci 1989). As Marc Edelman (2001) puts it "NSMs emerge out of the crisis of modernity and focus on struggles over symbolic, informational and cultural resources and rights" (289). This theory does not attempt to explain why movements appear at certain times, but instead explains the rise of a social movement as a response to a grievance or discontentedness with an issue in a post-industrial society (Edelman 2001). One of the most important things Melucci argues is that the conflict itself does not change, only the actors within it are capable of changing (Melucci 1989). The introduction of new actors within a social movement causes the movement to change from within. This means that the conflict (MTR mining) stays consistent, but because anybody is 
capable of joining the movement, then it is the identities of the people in the group that change (Vahabzadeh 2001).

I chose to use NSM theory to study the movement in Appalachia because of the importance for the movement of the cultural, political, and environmental aspects of MTR mining. By using this theory I can directly address the ways in which activists identify with their groups and what they think about other groups. These identities will prove to be important in the ways that each of my respondents align themselves politically and culturally within Appalachia. Alberto Melucci (1989) discusses how culture, identity, and politics are all vitally important in the creation of social movements. In the Appalachian Mountains, people are protesting the use of MTR because it is a particularly destructive type of mining affecting their homes, the surrounding environment, personal and collective identities, politics, and health (McNeil 2012; Scott 2010; Morrone and Buckley 2011; Stimeling 2012; Lewis 1993; Holzman 2011).

The primary stance American sociologists employ in the study of social movements are the Resource mobilization (RM) paradigm and political process theory (PPT) (Edelman 2001; Bevington and Dixon 2005). RM theory views social movements as rational responses by social actors trying to initiate social change by using social, economic, and cultural capital and mobilizing social actors (Buechler 1999; McCarthy and Zald 2001). This is often discussed in terms of the different types of capital a particular group has at its disposal in pursuit of its goals. The RM paradigm stresses the ability of movement members to acquire resources (capital, new members, goods, etc.). 
Resource mobilization proponents conceded RM was not well equipped to handle a wide variety of social movements, leading to the addition of the political opportunity structure theory (POS), which added the analysis of organizational strength and governmental vulnerabilities (Meyer 2004). Critics of this perspective point out POS ignores the cultural and identity aspects of these movements (Edelman 2001). Political process theory (PPT) is essentially an addendum to POS that views the issues being protested by a community as unjust, which motivates actors to join a movement group (Meyer 2004). Bevington and Dixon (2005) critique PPT for its retroactive view in which anything that helped a movement can be labeled as a political opportunity (187), covering everything from gaining members to lessening government repression. Because this analysis is retroactive, it only can be used when looking at a movement that has already started and ended.

For my project I began with the basic NSM theory described by Melucci, and added another dimension to it. Where nearly every article or book I have read on social movements primarily had two actors (the resistance group and the target), I added a third. Instead of looking at only one particular group within the social movement I chose to study two separate groups within one movement that approach the same issue with different tactics. This was done in a similar way as Kathleen Blee (2013) did in her research on how social movement organizations begin. While her work was more concerned with emergence, collective identity and actions were also important aspects to her study. She studied how the groups identified with one another and speculated on what the decisions being made would have on the future of the group. Similarly, I looked at tactics and motivations of established groups within the antiMTR movement. 
Each of the groups that have been studied in the past, such as the Coal River Mountain Watch (McNeil 2012), emerged out of necessity in response to the threat of MTR. When these separate groups began to work together by putting on jointly run protests and activities did it become a fully fleshed social movement. The recognition of the interconnectedness through multiple levels of the movement is imperative in framing and mobilizing supporters of a collectivity (Gahan and Pekarek 2013). By working together on larger protests and actions, the disparate parts of the anti-MTR movement became a coherent group that stands together. Instead of working on only one mountain or relatively small area, the larger anti-MTR movement now stands against the coal companies from a more equal platform.

Even though the general goal is the same, many of the groups cannot agree on which tactics are best. An important caveat here is that the same group can use varying tactics depending on the framework of what they are protesting in order to reach the same end goal (Gahan and Pekarek 2013). For instance, a mine blasting illegally could have direct action taken against them while a potential mine permit may be protested or petitioned against by the same group.

These changing tactics are exemplified by how the use of direct action has slowly been replaced by attempts to change the laws around MTR mining (Morrone and Buckley 2011; Wheeler 1976). The fluidity in which protest groups change their tactics is what helps them continue to gain members, who in turn slowly influence changes within the group. Belonging to a group is a result of actions that either reinforce or weaken a person's resolve that the collective identity of a group fits their own convictions, which is critical in the creation of 
collective action (Della Porta and Diani 1999, 87). This is noticeable within grassroots organizations such as Mountain Justice and R.A.M.P.S. as well as larger groups that have switched their tactics over time, much like the UMWA (McNeil 2012; Gahan and Pekarek 2013).

\section{Previous Research on MTR in Appalachia}

A hotly contested issue within the MTR debate is how West Virginia is often described as being literally coal, and mining is considered a masculine way to provide for a family (Scott 2007, 2010; Bell and York 2010). Some still see coal as the life-blood of West Virginia and do not want to see its extraction ended. Websites such as wvcoal.com and nma.com, created and run by Walker Cat (a mine equipment company) and the NMA (National Mining Association), present mountaintop removal mining in broad strokes and focus primarily on the reclamation work that has been done. These two websites use the same examples of reclaimed MTR mines and avoid the other environmental impacts that the mines have had on the area.

Instead they focus on the fact that coal is the biggest employer in the state, which is empirically false. According to the Work Force West Virginia report in March of 2014, only one coal company, Murray American Energy Inc. (an underground mining company), was ranked in the top 10 largest employers in the state at number 6 (Work Force West Virginia 2014). Patriot Coal was ranked $31^{\text {st }}$, Arch Coal was at $38^{\text {th }}$, and Elk Run Coal was $64^{\text {th }}$, and these are the only other coal companies in the top 100 employers in the state (Work Force West Virginia 2014). 
The consistently decreasing number of mining jobs in West Virginia is one of the primary concerns for the Sierra Club. One of the biggest contributors to the loss of coal mining jobs in West Virginia is the proliferation of MTR in the state (McNeil 2012, 68; Fox 1999, 169). Since mountaintop removal mining began to be used as the primary means of coal production in the state the employment in the coal fields has dropped precipitously, from a high of 125,669 in 1948 down to 14,281 in 2000 (McNeil 2012, 68). Their Beyond Coal campaign is aimed at coal producing states to educate residents about the coal industry and the problems that are associated with it. One of the most important things that these activist groups discuss is that there is a "life after coal". This is to teach miners, both current and former, that their skills do not apply only to coal (McNeil 2012, 63).

Situating this information within the cultural aspect of the mountaintop removal mining debate is a critically important part of the movements that oppose it. Rebecca Scott discusses hegemonic masculinity at length within the context of coal mining in West Virginia and how that relates to the cultures of Appalachia (Scott 2010). As she explains, mining has always been seen as a masculine field of work and the miners identify themselves as such. It is often portrayed as the strapping white man that brings home the money to provide for his family while his wife is at home (Scott 2010). This puts the male leaders of anti-MTR movement, such as Bo Webb and the late Larry Gibson, in the awkward situation of breaking these heteronormative positions, especially when considering many of the most vocal detractors of MTR are women (McNeil 2012). 
Bryan McNeil (2012) presents how this type of mining has damaged the small coal towns and the lives of the residents in them. His book is written about the Coal River Mountain Watch, which is an anti-MTR protest group located southwest of the state capital Charleston, West Virginia. The primary concern of his project was how the destruction of Coal River Mountain was affecting the communities that surrounded the mountain. It details in many ways how community, culture, and politics are portrayed in West Virginia, and why these things are so important in the fight against MTR. McNeil's research shows how grassroots organizations fight against the coal companies that have an extremely tight grip on the state government in West Virginia. An important connection that he makes in this book is how the politics espoused by both sides of the debate frame the environment and culture of West Virginia very differently.

Connecting the environmental harms to cultural harms MTR perpetuated on the people of West Virginia is vital in understanding the resistance to its use in the state. Travis Stimeling (2012) wrote a provocative article on the use of religion and music in Appalachia and how it affects MTR protests. Music was further used to describe this mining process as a desecration of God's mountains, and that it is an evil process which destroys many peoples way of life (Stimeling 2012). Religion, the environment, and culture are inextricably tangled in the hills of West Virginia, which is why the use of MTR is the center of such a heated debate amongst residents.

The West Virginia Coal Association used musical techniques in order to try and garner support for the coal industry by giving away free ringtones which only had four words in them 
"Coal is West Virginia" (Stimeling 2012,13). This was done to try and make more residents of the state identify with coal, and thus be amenable to the use of MTR in order to save both their own and the state's (coal) identity (Stimeling 2012). Other aspects of this campaign made sure to exemplify the fact that West Virginia is literally made of coal, and we need to extract it in order to keep the state, region, and country running (Stimeling 2012, 14). This helps show how closely people in West Virginia identify with coal and how it is considered an intrinsic part of their nature.

Using tactics like these is how groups on both sides of the issue garner support, be it through ringtones and music or masculinity and religion (Scott 2007; Stimeling 2012). These tactics are what help people get the word out and solidify the identities of the groups themselves. Understanding each of these different aspects of social movements is critical for learning about the tactics each group uses and why.

The questions that I am attempting to answer with this research will help further the understanding of identities and motivations of social movement actors. The different methods that are employed by the different groups reflect the motivations for the activists to join each respective group. How a person identifies with both the tactics and the group they are a part of, and how this varies between groups, is something that has not been given a lot of attention in previous research. Additionally, an aspect of social movements that rarely gets much attention is what causes people to stay involved for long periods of time. All of the studies mentioned above would often state how long a person had been active in the movement, but never 
discussed why they stayed involved. Studying what causes people to stay involved and why they leave can help these groups understand why they are or are not retaining their members.

\section{Methods}

The ethnographic observations and interviews I conducted were with members of two primary groups: the Sierra Club and Mountain Justice. I chose ethnographic methods because previous work done on the topic this way revealed detailed information on the identities, politics, and cultures at play in Appalachia (McNeil, 2012; Scott, 2010; Stimeling, 2011; Morrone and Buckley, 2011). Ethnographic studies strive to delve more deeply into the nuance of an issue by using multiple points of view. This allows for an in depth analysis of social movements on an intimate level in order to tell us why people are either for or against an issue and how they are trying to change it. As Robert Weiss (1994) said about the reasons to use qualitative interviews:

[I]f we depart from the survey approach in the direction of tailoring our interview to each respondent, we gain in the coherence, depth, and density of the material each respondent provides. We permit ourselves to be informed as we cannot be by brief answers to survey items. The report we ultimately write can provide readers with a fuller understanding of the experiences of our respondents. (Weiss 1994, 3)

I decided on interviews and observations for this particular reason. I carefully crafted my interview questions to be open-ended in order to glean as much information from the 
informants as possible. Employing an ethnographic approach allowed me to frame my research more clearly the longer I worked on it. By being there up close, I was able to clearly see what information is important and continuously refine my research questions and direction the longer I worked on this project (Ocejo 2013). This allowed for the information I gathered to be tailored to what I was studying, but still be open enough to learn about things I may have not originally thought about.

I drew from traditional NSM theory and Blee's (2013) framework in designing my research project. By approaching my project from this perspective I can clearly show that social movements are multifaceted and rarely as straightforward as they are often depicted. This is something which is highlighted by the differences between the groups I study. I used multiple research sites across the state of West Virginia where I gathered data, from rural places such as Kayford Mountain to large scale protests in the state capital. However, the bulk of my research was done with a regional student-run branch of the Sierra Club, the Student Sierra Coalition (SSC) at West Virginia University. Most of the members of the SSC are undergraduate students with a wide variety of majors. The spread covers physics, environmental geoscience, fashion, and engineering just to name a few. Much like Mountain Justice, the group is fairly evenly split male/female with slightly more women in each group. The biggest difference was that the members of Mountain Justice tended to be a few years older than the SSC members.

Drawing from the examples of Rebecca Scott and Bryan McNeil, among others, studying the issue of mountaintop removal mining in a similar fashion makes sense. The inductive nature of this research means that the research questions are clarified in the field over time (Ocejo 
2013; Weiss 1994). The fluidity within the research objectives is one of the greatest strengths of qualitative research. The reflexive nature of the research that is being done allows the discovery of which topic is most important to those being studied. This is why I used multiple questions in order to ascertain which of the topics were of the most importance to the people that I was speaking with.

I collected data by frequenting protests, weekend retreats, and regularly scheduled meetings. With the permission of the president of the SSC I attended the weekly meetings that are held by the group for six months. The purpose of an extended observation of a group like this is to establish what the normal operations for the group are. This includes everything from the structure of the group, what is discussed, which issues are most important, and how group actions are decided upon, among other important details.

I used semi-structured interviews as the primary source of data collection for this project. The interviews were designed to last between 30 and 60 minutes to ensure that the interviewee has enough time to give all of the information that they were comfortable with sharing (Weiss 1994, 56). The interviews lasted an average of 20 to 30 minutes and covered all the relevant details and more.

I chose my interviewees after spending a period of time with them ensuring that they were knowledgeable of the topic. Some of those in each group obviously were the most involved and well-versed in the topic while others were clearly less so. Once I identified good candidates to interview I approached them to inquire about an interview. The details covered in the interviews ranged from their personal motivations for being in the movement, to what their 
favorite actions have been, and more. Once I interviewed a few people here, I began snowball sampling from these well-informed individuals within each organization in order to do more quality interviews. Supplementing the snowball sampling, I also used the events that I attended to recruit more interviewees if I felt like they could meaningfully contribute.

Once participants agreed to the interview they were informed what the research project is on and how the information would be used. Once the formalities were seen to, I took a more relaxed approach to the interview. I recorded the interviews with a digital audio recorder as well as hand written notes to add supplementary detail. The reason both methods were used was to capture every word the interviewee says and jot down observations. These would include where we were, if they seemed nervous or confident, what their mood was, what they were wearing, etc. After the interviews concluded I listened to the interviews repeatedly and created a codebook and added my hand written observations to ensure that no data were overlooked.

At other events, such as a weekend retreat for Mountain Justice, R.A.M.P.S., and the Sierra Club (hosted by R.A.M.P.S.), I employed the same techniques in order to gather as much information as possible. I took notes on everything from who spoke the most and what people were wearing to which topics were talked about and simple demographic observations. These types of notes and observations are commonly used when doing qualitative fieldwork due to the amount of data that can be collected in this fashion (Ocejo 2013). Seemingly innocuous things that get noted down in this fashion can end up being critically important data points which need to be explored further (Weiss 1994, 9-11). This information is also used to create a 
context for the rest of the data. By using this context I can create a more complete picture of the events and why the people I spoke with act and think in the ways that they do.

I wanted to learn how activists joined and identified with the movement and how they viewed groups with other ideas within the movement. By conducting interviews on this topic it allowed me to gather background information about how they first became involved with the anti-MTR movement. This then logically moved the conversations into them discussing why they continue to be involved. The last question was designed to encourage activists to speak openly about what they think about other groups and the tactics that they use. This question was put at the end specifically because I wanted each of the interviewees to be at ease with me. Talking about themselves first was the easiest way to let them gain confidence in the conversation and relax, thus allowing them to be more open with me when discussing their opinion of other groups.

Seven of the interviewees were from the Sierra Club and the other five were from Mountain Justice. Due to the difficulty of meeting with the people from Mountain Justice, the interviews with them were a little bit longer to ensure all relevant information was collected. Secondary to the interviews, six months of participant observation was undertaken at various events put on by both groups. I also attended weekly meetings of the Student Sierra Coalition (SSC), as well as two weekend retreats, five protests, and four mixer-type events. Each of the events produced information that was relevant to different parts of the project.

By inserting myself into situations, and participating to an extent, where the activists were doing the actual resistance work gave me greater insight to this issues at hand. Similar to 
the way that Bryan McNeil (2012) and Travis Stimeling (2012) gathered their data, I went to events and spoke to a large number of people. Both of those pieces speak to the tactics and reasons that are found throughout the anti-MTR movement which spoke critically to the development of my own research. Using those, and many other, articles I found a niche in the research that was lacking in analysis. Starting from there, I began my study with the information that was available nearby and expanded from there.

\section{Findings}

My findings are laid out in the order I asked the interviewees the questions and are broken down into subsections. The first thing that I inquired about was what motivates people of different backgrounds to join this particular movement. After a couple of months I began to delineate the motivations I was hearing into two basic categories: Learned and Experiential motivations. The differences are fairly obvious, but I will detail them more explicitly in the next section. I next moved on to the length of their involvement and why they continue to stay involved in this movement. The reasons I got from each person I interviewed, as well as the others that I only spoke with in passing, were fairly similar. The main theme I learned here is that they choose to keep at it because there is work still to be done and they are making a difference.

The tactics that my informants discussed proved to be one of the most interesting aspect of this research. There was a lot to be said for and against both the reformist and direct action approaches. From here I moved on to what these people thought about the other groups 
within the same movement. I learned about why my informants think the other groups are either worthwhile or merely wasting their time.

Lastly, I asked about joint actions that multiple groups put on in an effort to stop the use of MTR mining. Some of the people I spoke with at the events I attended believed that joint actions are the best way in which the fight against MTR can be pursued. Unfortunately, many of those that I interviewed had a limited knowledge of these events. With that being said, those that had attended these events offered valuable insight and reasons for why they support them.

\section{Personal Motivations}

Motivations for joining a social movement vary from person to person and can be broken down into groups in various ways. In McNeil's (2012) work, the people he spoke with got involved because their land and way of life were being directly affected by the MTR mine on Coal River Mountain. Bell and York (2010) discuss how the economics of extractive resources can be a driving force for joining a social movement, with the loss of both high paying jobs and land (112). Yet at the same time the economic benefits to some people and small towns can be motivating factors for people to defend the extraction of coal. It can also be argued that the anti-MTR groups can be perceived as the reason for the loss of mining jobs in a particular area, even though the continued and growing use of MTR actually causes more job loss than anything (McNeil 2012; Morrone and Buckely 2010). Fox detailed how masculinity and community also can be influential in this area. These examples and many others (Morrone and Buckley 2010; 
Stimeling 2012; Fox 1999; Holzman 2011; Lewis 1993; and Palmer et al. 2010) all deal with the motivating forces behind joining the anti-MTR movement in West Virginia.

The specific reasons I found for each person's motivation to join an environmental movement are all somewhat different but have some noticeable consistencies. Each person I interviewed mentioned that the reason they joined the Sierra Club or Mountain Justice was because of something they had either learned or experienced personally. Now, the reasons were more varied within the Sierra Club. This makes sense because that organization covers a much broader number topics than just mountaintop removal mining. Within the Mountain Justice organization the reasons people joined are more similar to one another.

Four of the informants, three from Mountain Justice and one from the Sierra Club, specifically cited MTR as their reasons for joining the movement. Two of them joined Mountain Justice and have stuck with them for years. The others bounced between various groups before one landed in Mountain Justice and the last in the Sierra Club. The eight informants that did not cite MTR as the direct reason for joining an environmental group talked about fracking, water pollution, climate change, energy efficiency, and land conservation, among others, as reasons for getting involved originally. This is the way in which the majority of the people I spoke to ended up in the groups they currently are in.

A few began with other environmental groups dealing with fossil fuels of a wide variety or helping in areas that have been affected by disasters (recently with the water crisis in Charleston, West Virginia). These situations had direct impacts on the majority of the informants for this research and was the catalyst which pushed them into more active roles in 
environmental movements. One of the SSC members I interviewed is a sophomore design major at WVU and in regards to this she said, "I never knew lots about environmental issues until that chemical spill in Charleston [W.V.], even though I'm from here". She went on to talk about how that was the beginning of her interest in the environment in her home state of West Virginia, which inevitably led her to mountaintop removal mining.

While all of the people interviewed had various reasons for joining an environmental group, they all eventually landed on one topic that they were much more passionate about than the rest. In this case, all of those spoken to believe that mountaintop removal mining is the biggest issue that needs to be addressed in Appalachia. For their own specific reasons they feel like the group they are with has the greatest chance at doing something meaningful in the fight against MTR. Most of the interviewees said that fighting against MTR started on a personal level. Although it did not start personally for everybody, on some level they each feel a strong connection to the mountains of Appalachia. One of those that said MTR did not start off personally was a mining engineering major. He said, "I got into mining because I knew l'd make a ton of money. But then I learned 'bout what it's doing to the state, like, on a big scale". One of his biggest concerns was that the mines are not going to last forever and the towns that survived on coal money are shrinking. He went on to tell me how he wants to work in the field but that he believes that the mining can and should be done in a safer manner.

The way that people connect and identify with the Appalachian Mountains is explored thoroughly by Bryan McNeil (2012). McNeil (2012) discussed how the people that live in these parts of West Virginia identify so closely with the mountains that they feel the destruction of 
the land is akin to killing a family member. This identification with each other and the surrounding environment clearly resonates with Melucci's theory of social movements. These tight knit communities largely share a common identity that is comprised of political views and cultural norms. Melucci writes, "Individuals acting collectively 'construct' their action by means of 'organized' investments: they define in cognitive terms the field of possibilities and limits they perceive while at the same time activating their relationships so as to give sense to their 'being together' and to the goals they pursue" (Johnston and Klandermans 1995, 43). By identifying in this way the people in the movement are more clearly connected to one another. All those interviewed were rather forthcoming in the development of their stance on MTR and why they ended up in the groups they now support.

One of the informants was fairly new to the issue but from the way they spoke about it, it was clear they had done their research and quickly became well versed in the nuances of MTR. She told me that the interest in MTR originally stemmed from wanting to help people in Appalachia that are being underrepresented or ignored. The first stop was with the food recovery network which lead, through a convoluted series of steps, to Mountain Justice because their mission and actions lined up with her personal beliefs. She talked about how some of her older friends that were already active in environmental issues were the people that originally introduced her to the movement. She remembered, "They were super supportive, like, they told me to find which [group] fit me the best and keep with it. This stuff don't change fast".

One of the male members in the Student Sierra Coalition at WVU followed a different path into this movement. He told me that his entrance into the Sierra Club was a result of his 
upbringing putting a premium on material things and ignoring the environment. Although he is only 19 years old he has already come to the conclusion that protection of the environment is an important issue that is largely ignored. He told me, "I had no idea what I was doing at first. I just went to random meetings for groups that I had never heard of and listened to them talk. Some of them were ridiculous to me, but others made good points. Over the course of, I dunno, like, five or six months, I decided that I should focus on WV since that's where I live now and I like the mountains". He went on to describe how he came to learn of mountaintop removal mining and decided that it would be prudent to go and visit a mine site. This led him to the Mountain Justice weekend retreat at Kayford Mountain.

The two biggest differences between many of the activists that are involved with the anti-MTR fight have witnessed and experienced what MTR does, while others have only read about the destruction it causes. This is leads them to join the anti-MTR movement for either learned reasons (the destruction of mountains) or for experiential reasons (the destruction of their home/town). These two different experiences show the wide variety of ways in which people can be drawn to environmental movements. The reasons that each person has differs from one another yet they still end up in the same place. Being introduced to it by friends that are already involved is the most common way in which people become active, but there are others who end up here purely out of self-motivation. The motivations that brought each person to this topic influences the way that they believe that it should be fought. These two interviewees exemplify each of those reasons for joining; one decided to become involved from a learned position whereas the other was invested because of experiences. 
No matter which way the person decided that they were going to protest the use of MTR they all spoke of it as a personal matter. Nearly everybody I spoke with and observed, talked about the destruction of the mountains in humanistic terms. This method of mining was regarded as "rape" or "murder" by many people. By identifying with the mountains and taking a personal stance on the way that they are being treated is a normal outlook from people within the movement. Now, with that being said, the vehemence of this position differed by each person, which is why some people take so long to find a group within which they identify the most.

Not only did most of the interviewees say they bounced between groups, at the meetings, retreats, and actions a great deal of people mentioned how they did the same. Some of the people that I observed were still discovering which group they identified the most with and consequently would float between groups at the larger events. This way they can find the group which mirrors their own personal stance on MTR. If somebody was more interested in direct action they would migrate towards the Mountain Justice or R.A.M.P.S. camps and if they wanted to work more within the law they would tend to lean towards the Sierra Club.

Generally speaking, each of the people that joined in the fight against MTR in West Virginia started out with various motivations, but the longer they stay involved the more similar their motivations become. Those that joined for, what I called, learned reasons, quickly began to think of the issue emotionally. Because this issue is so frequently debated in emotional, and even humanistic, terms it makes sense that each of these activists became emotionally invested even if they did not start off that way. 


\section{Staying Involved}

Staying involved with a particular social movement is not something that is always given a lot of attention. Previous works have discussed the length of time some people have been involved (Morrone and Buckley 2012; McNeil 2012; Scott 2010; and Blee 2013), while others forgo this bit of information altogether (Stimeling 2012; Fox 1999). The people that stay involved with a social movement over an extended period of time can offer invaluable information about the direction their particular group is taking and how it has changed over time (Blee 2013). By understanding the long-term effects of how an activist group has changed over time social scientists can create and apply theory more readily to a specific movement.

Even with the variance between interviewees, and others that I talked to in passing, the general reason that people stay involved is because they feel as though "the work is not done". That little phrase has a myriad of meanings, even when only considering the topic of MTR. One of the informants said this in a particularly poignant way, "Every time we get a piece of legislation passed, or block one, we are one step closer to our goal. But, that doesn't mean we're going to stop. We can't stop, this is too important to all of us". This point was echoed similarly by a number of other people that I spoke with. Another person said simply, "We won't stop until they do".

Apart from this somewhat general answer, people also had personal reasons for staying. Even when somebody is starting to feel down on the movement or think they are not doing anything productive, another person will step up and help them become revitalized in their 
convictions. Many people discussed how, at one point or another, either they or a friend of theirs was flailing and needed reassurance that what they were doing mattered. Although on occasion people will stop being active in the movement and nobody is able to convince them that their input/activity matters. However, they also stop for other reasons such as burning out or for personal reasons. Only two of the people that I spoke with told of people that they knew that completely stopped their activities in environmental matters.

From the observations and interviews, it appears that people seldom completely stop being an activist. More often than not, if a person drops out of contact with a group it is because they ended up in another group that more closely mirrors their personal beliefs on the issue. There are a couple of reasons for this to occur, however most frequently, from what was said, it is because they do not think that the tactics of the group they left was the proper way to protest the issue. Another possible reason for an activist to leave one group is because they may disagree with the tactics that are being used in that group.

The majority of the people that I spoke interviewed for this project had only been involved with anti-MTR movement for less than three years. Yet, even in such a short amount of time they had observed and experienced the ways in which a group can gain and lose members, as well as watch how tactics change with time. Although they agree that the work is not done, the ways in which they go about their work often changes with time.

$\underline{\text { Tactics }}$ 
Tactics are an integral aspect of social movements, and as such they have received a lot of attention from scholars. There are two primary types of tactics that are used in a protest or a social movement; they are direct action and reformist action. Direct actions are the physical protests that are law abiding and a show of force, these include parades, sit-ins, marches, and other types of protest. There are also what are called illegal direct actions which are the more extreme forms of resistance. These include industrial sabotage, walking onto active mine sites, blocking access to mine sites or equipment, and so on. On the other side of the issue is the use of reformist actions which include proposed legislative changes, petitioning, and taking issues to court. Some scholars of social movements focus primarily on the use of direct actions (McNeil 2012; Blee 2013; Morrone and Buckely 2011; Wheeler 1976), while others have focused more on reformist actions (Channell 2011; Davis and Duffy 2009; Evans 2010; Fox 1999; Scipes 2011).

The use of the different tactics can be partially responsible for drawing a person to join that group. Those that learn about what MTR does to the land tend to be more likely to join a reformist type group (i.e. the Sierra Club), while those that experienced it are more likely to join a direct action group (i.e. Mountain Justice). It is because of how these two types of actions draw different people that I ended up choosing these two groups to study. I wanted to ensure that I was representing the two general sides of this social movement.

The most contentious of the tactics that are used are illegal direct actions. Drawing from Morrone and Buckley's (2011) research, those that use illegal direct actions today are more reminiscent of the protestors in 1970's Kentucky. This type of action is seen as more acceptable 
by some people now because it was a valid tactic used in the past. Della Porta and Diani (1999) address this by discussing how radical aspects of a movement tend to dwindle through time and the moderates move to the fore. Yet, if the radicals cause too much disruption then the protest group begins to demobilize (189-190). It is for this reasons that a lot of the illegal actions are typically done in smaller groups.

There were a couple of points that nearly every interviewee agreed on when discussing the tactics they, and others, use in the fight against mountaintop removal mining. The most interesting point that each of these people made was that nearly all agreed that sometimes peaceful, law-abiding protests and actions were not the best way to get the point across. All but two agreed that on occasion illegal actions are the only way to get their message across. Now of the ten that agreed, nine said that it was a "last resort" type of move. Only if going through official channels and following the law failed them entirely would they even be open to the idea of breaking the law. One of the participants said they would, "consider walking onto an active mine site... in order to shut it down... if a peaceful protest was not doing anything". While another said that they thought these types of actions are a necessary part of the resistance movement and "without doing it they won't take us seriously".

One of the most important aspects of the interviews was asking each person directly about which tactics they preferred and why, as well as those of the group they are a part of. As was expected, each person identified with the group they supported. As described by Melucci and other SM theorists, this identification with a type of tactic is what drives them, whether it be reformist or direct action tactics. With the constantly changing makeup of the groups, 
through new members and the loss of older members, the identity of the group as a whole changes slowly. Which is turn causes the stance on these varying tactics to be continually fluid. Yet, the shift in supported tactics does not only flow in one direction, occasionally a reformist may begin to use direct action tactics and vice versa.

Many of the members of the Sierra Club mentioned that on occasion the only way to get real results is by breaking the law and moving directly against the coal companies. One of the leaders of the Student Sierra Coalition said; "MTR sites are the perfect examples of where the law isn't really doing anything for them... they're either going to stay there and suffer, leave, or stay there and do something about it". This stance is reflected throughout much of the SSC at WVU. Only two of the people that were interviewed said that they believed that breaking the law through direct action was never the proper course of action. One of them said, "No. I don't think anybody should [break the law] for this issue. It just sets back everybody who's trying to make changes the right way". These two were the only interviewees that directly said they would not support that type of action, but this sentiment resonated, minimally, with some of those at the larger group events. However, the vast majority would not rule out a possible plan of action just because they did not like it.

The Sierra Club is much more focused on petitioning and raising awareness in hopes of creating legislative change, while Mountain Justice prefers to use direct actions against mines and mining companies. While this is a well-known difference between the groups, it does not account for the fact a lot of members of both groups either have or are willing to dabble with illegal direct actions. This is not to say everybody is willing to do so, however ten of the twelve 
interviewees said they are willing to. The other two echoed each other by stating, "that type of action is stupid. It makes all of us look like nutjobs." And, "Those people are hurting what us saner people are trying to accomplish". The acceptance of these actions is a complicated issue. Between those two poles there is a wide variety of acceptance on these methods.

Agreeing with the use of illegal direct action tactics has many sides to it. Some people are accepting of walking on to active mine sites to force a shutdown, while others want to take it further still. Some people within the more radical side of the movement want to revert back to the old tactics of sabotaging the equipment the mines use. I only learned of this through second hand information. Also, an important thing to note is that just because a person is supportive of these tactics it does not mean that they participate in them. While I did not speak with anybody that had been directly involved in the use of this tactic, some of those I spoke with "know a guy". However, that is much more frowned upon within the movement than walking-on to mines.

The tactics that I learned from my observations and interviews show the wide variety of ways in which this issue is protested. The overwhelming majority of people that I both spoke with in passing and interviewed prefer to stay within the law and think legislative changes are the best course for long term change. While discussing the tactics that they, and other groups, use the opinion of other groups (whether they use the same tactics or not) were spoken about frequently. 
Many times, other groups are only spoken about in passing by authors of these sorts of research projects. While most articles refer to opinions of others briefly (McNeil 2012; Diani 2009; Stimeling 2012), Kathleen Blee (2013) spoke about how these groups view one another in her piece on emerging grassroots activist groups. She paired the four groups off and discussed how they viewed one another (Blee 2013). Depicting how groups on any side of the same issue think of one another provides useful insight on the direction the movement may take. What I learned from my interviewees was that opinions of other groups is important in how they view themselves within the context of the larger movement.

To make it simple, members of the Sierra Club were asked about Mountain Justice and R.A.M.P.S., and Mountain Justice Members were asked about the other two. This was done to focus the data instead of having the interviewees talk about whichever groups they could think of. When the interviewees were asked about the other groups some of them thought that other groups were doing good work, while others thought some of the groups are not doing as much as they should be. That being said, each person could agree on one thing: Working together was helpful for everybody.

However, each group only wants to work together on certain aspects which makes it harder for everybody. Large scale actions are often worked on together, the events that are shown in the news, but not all of the smaller demonstrations. For instance, a smaller group could want help protesting in a small mining town, and the larger groups may or may not help depending on a wide variety of circumstances. While that is just a hypothetical, it is a very real possibility. A frequent reason that I heard from those I interviewed was that support depended 
on whether or not "[they] like how they're doin' it". The Sierra Club wants help petitioning and lobbying for change without getting their hands dirty in the direct action movements of Mountain Justice. While Mountain Justice wants help with their actions but they feel like helping sign papers is not always worth the time and energy for something that "probably will amount to nothing", as one participant said.

This notion of working together was debated at some length during both weekend retreats that I attended. At the Mountain Justice summit many of the people thought that petitioning was a good way to get new people involved, however most did not think it would amount to much. At the Sierra Club weekend event, SierraFest, peaceful protests and petition signing were discussed as being the best option because it involved more people and made their stance known without breaking the law. At both events, there were those that played devil's advocate on either side of this debate. The divide that this creates within the anti-MTR movement is what makes large scale, multi-group events very difficult to set up. Without agreeing on this particularly important item, a fully cohesive social movement has not, and probably will not, occur.

The Sierra Club members generally held those in Mountain Justice in a high regard for the actions that they do and the amount of information they disseminate. On the other hand the Mountain Justice members, while being friendly with the Sierra Club, thought they were not doing as much as they could. A Mountain Justice member said, "I think that they do good work, but they try to do too many things at once and some things just fall to the back-burner". I noticed this as well while attending regular meetings with the SSC. Each meeting lasted roughly 
an hour, and on occasion would cover as many as eight topics in that time. So it is easy to see how people from other groups could think that the Sierra Club tries to tackle too many projects at one time. A common occurrence at these meetings was that if a tricky issue came up and nobody had a clever or new way to attack the problem they would just move off of it and talk about something else. This rapid change of topic at the meetings makes the accusations from the Mountain Justice members seem to be well founded.

On the other hand, the Sierra Club is a national organization which has a much greater number of members. The greater number of members enables them to be able to work on a greater number of projects simultaneously. While MTR is not one of the biggest issues that they try to tackle, it falls into their scope as a contributor to climate change. So it does get attention from the organization, but not enough in the eyes of smaller groups such as Mountain Justice. On the other side of that issue, members of the Sierra Club that were spoken to believe that by just focusing on the issue of MTR Mountain Justice is limiting themselves. Many of them think that if they broadened their scope more effectively to include all of the issues that affect the mountains they would have greater success at protecting them. That approach is a bit of a double-edged sword though. This is precisely the issue that the smaller, grassroots organizations have with the national Sierra Club. A common belief among people from these smaller groups is that if they focus on small issues and have more decisive victories with them, they will eventually build to a tipping point in which they can make more sweeping changes. One member of Mountain Justice eluded to exactly that when he said, "the little things add up, then they can't ignore us". 
Now, these opinions are not the official stances of either group, they are based off of what the interviewees said and what I observed. The official stance of each group can be seen on their websites and they simply state that they wish to end the use of MTR. The consistency in the responses that were obtained from each group suggest the beginning of a pattern. Each group generally held the other in high regard, aside from some procedural and focus issues, each believed that the other was doing good work. Which begs the question, why are there not more joint actions between groups?

What both camps said bout the other is that they believe they are doing good work. However, because their focus is different, they believe that the tactics that they are using could use some refocussing. Apart from the debate on reform vs. direct action, each side held the other in high regard. One of the SSC members said, "just 'cause we do it different from them, doesn't mean we can't both be right".

\section{Joint Actions}

Joint actions have been discussed by a couple of authors, but it has never been a heavily covered aspect. It is usually only talked about when the main group that is being studied is attending a large multi-group action (McNeil 2012; Blee 2013; Morrone and Buckley 2012). However, the majority of the articles that are written about social movements focus primarily on a single group and their accomplishments. Learning about joint actions while doing my research was something that I was only interesting in in passing but turned out to be more interesting than I had anticipated. 
Joint actions are ideal for everybody that is active in the anti-MTR movement in West Virginia. This is because each group is capable of reaching a larger audience when they work together. Unfortunately, getting multiple groups together is an arduous task that few people are capable of pulling off. This causes issues when it comes to joint actions because students typically do not have the time or money that is necessary to attend large actions, let alone help set them up. Half of the people interviewed did manage to go to a weekend long retreat that was put on by Mountain Justice and R.A.M.P.S. in the fall of 2014. Others went to a different weekend retreat that was sponsored by the Sierra Club earlier in the year. The two events I, and some interviewees, attended were quite different in what they were trying to accomplish.

The Mountain Justice summit was designed to raise awareness about a myriad of issues that are affecting West Virginia. The two biggest topics at that event were mountaintop removal mining and campaign strategies and tactics throughout the state. Clean water was also an important issue because the event happened roughly two months after the chemical spill in the Elk River that left a couple hundred thousand residents without clean water for weeks. However, this was a minor issue that was covered quickly. The majority of the time at this event was centered on MTR mining and its effects on the people and the state. There were workshops and community organizing talks that were focused on becoming a leader in the movement, while others were specifically informational meetings. All of these sessions were mostly focused on the new attendees and the things they can do to become more involved in the movement. 
The Sierra Club event, SierraFest, was held a month prior to the Mountain Justice summit. This weekend retreat was not quite as specific as the Mountain Justice event. It covered a much wider number of topics relevant to West Virginia. The majority of the first day was spent on the topics of fracking and climate change, while MTR was relegated to a few hours the second day. Each of the topics that were discussed sounded like conference presentations. The formal feel of the weekend make it seem like those in charge were much more concerned with only relaying information to those in attendance. While the dissemination of information is crucial in environmental movements, doing so in such an ordered way made it seem like we were only there to listen. When speaking of MTR the presenters were primarily focused on successful litigation that had already happened. There was mention of potential future actions but, it was mostly in theoretical terms and glossed over. Apart from stating that this weekend retreat would happen again next year there was no concrete mention of any other types of actions.

I learned less information from this weekend than I had anticipated. I had hoped to learn more about how the Sierra Club plans to work on the MTR issue in the future, but it was covered so quickly that I did not learn much new information. However, it did give a more poignant juxtaposition to the other environmental groups within the state concerning how they operate. This weekend showed me that such a large organization like the Sierra Club operates in a more hierarchical fashion than the grassroots organizations such as Mountain Justice. By that I mean everything was done in a very particular way like a well-choreographed series of movements between topics. Other groups have a more fluid feel to them. For example, these 
informational sessions never ran over their allotted time, whereas some of the smaller groups would run long because of questions or a point that somebody else brought up.

The differences between the Sierra Club's and Mountain Justice's group structures are fairly common in social movements. The Sierra Club has a vertical structure, a hierarchical setup where those at the top delegate and disseminate information to those below them. Mountain Justice has a horizontal structure, where everybody has a more equal voice. It is for this reason that Mountain Justice and other grassroots organizations can act more quickly than groups that have vertical structures.

Although these two examples were huge successes, the people that attended each one were overwhelmingly from the host group. I consider these events to be successful because they achieved their primary goal of disseminating information and trying to include newcomers. Even though these are annual events that occur at roughly the same time every year participants from the non-hosting group are drastically underrepresented. This insight comes from my own observations from attending each event and interviews of those who had attended as well. Using these two events as a basis for how well the groups work together on an issue is a good place to start. Understanding why the groups only work together sometimes is beyond the scope of this research project.

Joint actions do not have not been given a large amount of attention in the past and those that have do not discuss them in the same way that I have (Blee 2013; Morrone and Buckley 2012; McNeil 2012; Ackland and O'Neil 2011; Johnson, Agnone, and McCarthy 2010). Therefore many of my conclusions about how joint actions work in this particular type of social 
movement have to be speculative. Based on what I did learn, there are a few reasons why these groups only work together sometimes. The smaller, grassroots organizations like Mountain Justice do not tend to work with national organizations like the Sierra Club because of the speed in which they move. The Mountain Justice group, and others that are similar in size, plan and mobilize much more quickly than larger groups (Morrone and Buckley 2012). This difference in pace creates frustration which prevents them from trying to work together very often. However, they still try to work together sometimes because it is mutually beneficial. The smaller groups get more coverage and attention when teaming up with larger groups like the Sierra Club (Ackland and O'Neil 2011; Blee 2013). I was told that in return the Sierra Club gains local contacts which helps them grow. The other big sticking point that creates tension between the two groups are the tactics that are employed. The use of direct action, of any sort, can be an issue to nationally known organizations if it is not the image they are trying to create for themselves. At the same time, the smaller groups can be frustrated by attacking the issue only from one side. These groups believe that changing the laws in order to protect the mountains are a noble end-goal, but that they should be acting in the here-and-now at the same time (Johnson, Agnone, andMcCarthy 2010).

\section{Conclusions}

In this study I examined a wide variety of reasons for people to join an environmental movement. In this case, the reasons I was given were clearly defined between the two groups. Those that joined the Sierra Club were only secondarily affected and had little firsthand 
knowledge of what MTR does to the mountains. Those in Mountain Justice, meanwhile had significantly more firsthand experience of MTR in their daily lives. Another important distinction to make here is that the Mountain Justice members joined an environmental movement specifically because of MTR. Meanwhile, the Sierra Club members that I spoke with got involved with the anti-MTR movement after they had already joined the Sierra Club for a different environmental reason.

The people that continue to be active in environmental movements for long periods of time more closely identify with the movement than those who are active for a short time. This is most frequently seen at the college level. The members of the SSC at West Virginia University change with some regularity, but those that go to all the meetings and events are much more likely to continue with the movement after the end of college. When speaking to these people it was revealed that it was rare for somebody to go from highly involved to abandoning the projects they were working on entirely. Whenever this does happen it is typically because they encountered heavy resistance and felt as though their efforts were in vain.

People from each group view each other differently. While they can agree on the main point of MTR needing to be ended, they often disagree on how to stop it. This causes friction between the two groups and is a frequent cause of debate. The legality of certain protest tactics is the most contentious part of this social movement. While everybody that I spoke to agrees that legislative change to end MTR is the ultimate goal, the activists are split on whether or not illegal protests and sabotage should be used in their efforts. The split between those that prefer reformist over direct action, and vice versa, falls in line with the groups of which they 
are a part. Those in the Sierra Club tend to prefer reform while those in Mountain Justice prefer direct action, but most think that they should stay within the law. Some believe this does nothing but undermine the movement and paint everybody that is involved as a dangerous radical. While some others think that this is the only way that they will be taken seriously. One informant said, "If the law won't stop them, then we'll have to do it ourselves".

My research has shown that there is a large amount of variance even within a single social movement. By studying two separate groups at the same time it helps better contextualize previous research such as McNeil's (2012) and Scott's (2010). This context provides a more solid foundation for the other works that have been done on mining in Appalachia. It shows that there are a variety of ways to identify with this movement and how different groups approach the conflict. This also explains how these groups work within the larger social movement as a whole. By viewing multiple approaches to the same issue it gives us a more detailed makeup of the entire movement. We learn why multiple tactics are used and how they are used effectively by various groups.

While this is not as deeply researched as those two books were, I am confident that this research provides a solid foundation for a more holistic approach to the anti-MTR movement in West Virginia. The relatively short amount of time spent with the two groups and the number of interviews makes this project a stepping stone for future research. What I learned here points out that more research needs to be done on these issues. As one of my informants told me when referring to the anti-MTR protests he said, "We just need to continue", and I think other social scientists should do the same. 
Focused research on the different tactics that these groups use could provide detailed information about why people prefer one group's tactics over another based on their own past. Another possibility is studying how groups retain members by adjusting their tactics over time, which could give insight into how new members influence a group. These are just two avenues of research that were opened up to me by the study I conducted. Bearing that in mind, there are many other possible routes to expand on from the foundation I created. 


\section{Bibliography}

Ackland, Robert. Mathieu O'Neil. (2011) "Online Collective Identity: The Case of the Environmental Movement." Social Networks 33(3): 177-190

Bell, Shannon and Richard York (2010) "Community Economic Identity: The Coal Industry and Ideology Construction in West Virginia" Rural Sociology 75(1): 111-143

Bevington, Douglas and Chris Dixon. (2005) "Movement-Relevant Theory: Rethinking Social Movement Scholarship and Activism" Social Movement Studies 4(3): 185-208

Blee, Kathleen. 2013. "How Options Disappear: Causality and Emergence in Grassroots Activist Groups." American Journal of Sociology 119(3): 655-681

Brown, J. B. (1992) "The Wave Theory of American Social Movements." City \& Society, 6(1): 26-45.

Buechler, Steven M. (1995) "New Social Movement Theories." The Sociological Quarterly 36(3): 441464

Buechler, Steven M. (1999) Social Movements in Advanced Capitalism. Oxford University Press

Channell, E. S. (2011) “Coal Miners' Slaughter: Corporate Power, Questionable Laws, and Impunity." North American Dialogue 14(1): 12-22

Davis, Charles E. and Duffy, Robert J. (2009) "King Coal vs. Reclamation: Federal Regulation of Mountaintop Removal Mining in Appalachia" Administration \& Society October 2009 (41): 674 692.

Della Porta, Donatella. Mario Diani. (1999) Social Movements: An Introduction. Oxford: Blackwell

Diani, Mario. (2009) "The Structural Bases of Protest Events: Multiple Memberships and Civil Society Networks in the 15 February 2003 Anti-War Demonstrations" Acta Sociologica 52(1): 63-83

Edelman, Marc. (2001) "Social Movements: Changing Paradigms and Forms of Politics" Annual Review of Anthropology 30, 285-317

Evans, Sam (2010) "Voices from the Desecrated Places: A Journey to End Mountaintop Removal Mining" Harvard Environmental Law Review 34, 521-576

Fox, J. (1999)"Mountaintop Removal in West Virginia: An Environmental Sacrifice Zone." Organization \& Environment 12(2): 163-183

Gahan, Peter and Andreas Pekarek (2013) "Social Movement Theory, Collective Action Frames, and Union Theory: A Critique and Extension" British Journal of Industrial Relations 51(4): 754-776 
Habermas, Jurgen. (1984-1987) "The Theory of Communicative Action" (two volumes) Translated by Thomas McCarthy, Boston: Beacon Press

Holzman, David C. (2011) "Mountaintop Removal Mining: Digging Into Community Health Concerns" Environmental Health Perspectives 119 (11): A476 - A483

Huber, Patrick (2006) "Red Necks and Red Bandanas: Appalachian Coal Miners and the Coloring of Union Identity, 1912-1936." Western Folklore, Winter.

Johnson Erik W., Jon Agnone, and John D. McCarthy (2010) “Movement Organizations, Synergistic Tactics and Environmental Public Policy." Social Forces 88(5): 2267-2292

Johnston, Hank and Bert Klandermans. (1995) "Social Movements and Culture." University of Minnesota Press. 41-63

King, Martin Luther, Jr. (16 April 1963) “Letters from Birmingham Jail”.

Langman, L. (2013) "Occupy: A New New Social Movement." Current Sociology 61(4): 510-524

Lewis, Ronald (1993) "Appalachian Restructuring in Historical Perspective: Coal, Culture and Social Change in West Virginia" Urban Studies 30(2): 299-308

McAdam, Doug and Snow, David A. (2010) Readings on Social Movements: Origins, Dynamics, and Outcomes. Oxford University Press

McCarthy John D. Mayer N. Zald (2001) "The Enduring Vitality of the Resource Mobilization Theory of Social Movements" Handbook of Sociological Theory (533-565)

McNeil, Bryan T. (2011) "Combating Mountaintop Removal: New Directions in the Fight Against Big Coal." University of Illinois Press

Melucci, Alberto. (1989) Nomad of the Present. Temple University Press

Meyer, David S. (2004) "Protest and Political Opportunities" Annual Review of Sociology 30 (August): 125-145

Morrone, Michele and Buckley, Geoffrey L. (2011) Mountains of Injustice: Social and Environmental Justice in Appalachia. Ohio University Press

Ocejo, Richard. (2013) Ethnography and the City. Routledge

Palmer, M. A., E. S. Bernhardt, W. H. Schlesinger, K. N. Eshleman, E. Foufoula-Georgiou, Hendryx, A. D. Lemly, G. E. Likens, O. L. Loucks, M. E. Power, P. S. White and P. R. Wilcock. (2010) "Mountaintop Mining Consequences." Science (Washington) 327 (5962):148-149 
Scipes, Kim. (2011) "Globalization From Below: Labor Activists Challenging the AFL-CIO Foreign Policy Program." Critical Sociology 38(2): 303-323

Scott, Rebecca R. (2007) "Dependent Masculinity and Political Culture in Pro-Mountaintop Removal Discourse: Or, How I Learned to Stop Worrying and Love the Dragline." Feminist Studies 33(3): 484-509

Scott, Rebecca R. (2010) Removing Mountains: Extracting Nature and Identity in the Appalachian Coalfields. University of Minnesota Press

Stimeling, Travis D. (2012) "Music, Place, and Identity in the Central Appalachian Mountaintop Removal Mining Debate." American Music 30(1): 1-29

Vahabzadeh, Peyman. (2001) "A Critique of Ultimate Referentiality in the New Social Movement Theory of Alberto Melucci." The Canadian Journal of Sociology 26(4): 611-633

Weiss, Robert S. (1994) “Learning From Strangers: The Art and Method of Qualitative Interview Studies." New York: Free Press

Wheeler, Hoyt N. (1976) "Mountaineer Mine Wars: An Analysis of the West Virginia Mine Wars of 1912-1913 and 1920-1921." The Business History Review 50(1)

Work Force West Virginia (2014). "Economic and Labor Market Information." Work Force West Virginia USA. Retrieved: October 27, 2014.

(http://workforcewv.org/Imi/EandWAnnual/Top100Employers.html) 